\title{
Adsorption of Sulfamethoxazole on Nanoporous Carbon Derived from Metal-Organic Frameworks
}

\section{Yuxin Li, Xie Quan}

Key Laboratory of Industrial Ecology and Environmental Engineering (Ministry of Education), School of Environmental Science and Technology, Dalian University of Technology, Dalian, China

Email: quanxie@dlut.edu.cn

How to cite this paper: Li, Y.X. and Quan, X. (2017) Adsorption of Sulfamethoxazole on Nanoporous Carbon Derived from Metal-Organic Frameworks. Journal of Geoscience and Environment Protection, 5, 1-8.

https://doi.org/10.4236/gep.2017.56001

Received: April 5, 2017

Accepted: June 9, 2017

Published: June 12, 2017

\begin{abstract}
Nanoporous Carbon (NPC) with high surface area of $1379 \mathrm{M}^{2} / \mathrm{G}$ and high proportion of micropore and mesopore volume of $2.90 \mathrm{Cm}^{3} / \mathrm{G}$ was prepared by carbonization of metal-organic frameworks ZIF-8. The adsorption of NPC towards the representative sulfonamide antibiotics sulfamethoxazole (SMX) from aqueous solutions was explored, in comparison with powder active carbon (AC). The adsorption kinetics and isotherms showed that the maximum adsorption capacity $\left(\mathrm{Q}_{\mathrm{m}}\right)$ of NPC toward SMX was $757 \mathrm{Mg} / \mathrm{G}$, around 2 times than that of AC adsorption. The high adsorption affinity of NPC was related to the high surface area and special Mic/Mesopore structure. The pore-filling mechanism as well as electrostatic interaction had important influence on the high adsorption of NPC. The results implied that nanoporous carbon derived from mofs could remove the contaminants from aqueous solutions effectively, and would be a promising adsorbent for the removal of contaminants in the future.
\end{abstract}

\section{Keywords}

Metal-Organic Frameworks, Sulfamethoxazole, Adsorption, Mic/Mesopore

\section{Introduction}

In recent years, many researchers found that some Pharmaceutical and Personal Care Products (PPCPs) and Endocrine Disrupting Chemicals (EDCs) exist in natural water and drinking water. This kind of contaminants can affect the growth and reproduction of aquatic organisms, having negative effects on human health through the biological accumulation [1]. Tracing to the source, researchers found that the sewage treatment process could not effectively deal with 
these pollutants [2]. These contaminants in the sewage treatment plant water mainly come from domestic sewage. Antibiotics and other drugs used by humans cannot be completely absorbed by body, and excreted through urine. At the same time, a variety of detergents and personal care products flown into the urban domestic sewage. Therefore, it is very important to have a highly efficient and targeted wastewater treatment method.

Traditional wastewater treatment methods include Gas floatation process, adsorption, membrane technology and advanced oxidation. As a wide-application and good-effect processing method, adsorption is high efficiency, low energy consumption and without by-product. Carbon materials are widely used in the field of adsorption due to their large specific surface area and pore structure, represented by activated carbon, silica gel and zeolite. According to different morphology, the types of activated carbon are divided into powder, granular and fibrous. The pore size distribution of activated carbon, used for the adsorption of pollutants in water, is very wide. Metal organic frameworks (MOFs), polymers with three-dimension pore structure, have been developed rapidly in last ten years. MOFs have the highest specific surface areas reported to date for porous materials (up to $6200 \mathrm{~m}^{2} / \mathrm{g}$ ) [3]. Nanoporous carbon (NPC) materials with high surface area and good chemistry stability, carbonated from MOFs, have been the research hotpot owing to their extensive applications in various fields, including contaminants adsorption, gas uptake and super capacitors. In this study, the ZIFs is a type of metal organic framework material whose organic framework based on nitrogen heterocycles. The stability of the structure is stronger than those whose organic frameworks based on carboxyl. In this work, a typical sulfonamide antibiotic, sulfamethoxazole (SMX), was selected as target pollutants to examine the adsorption behavior of nanoporous carbon derived from ZIF-8 [4].

\section{Experimental Section}

\subsection{Materials and Methods}

ZIF-8 was synthesized referring to the reported method, zinc salts $\left(\mathrm{Zn}\left(\mathrm{NO}_{3}\right)_{2}\right.$ or $\left.\mathrm{Zn}\left(\mathrm{CH}_{3} \mathrm{COO}\right)_{2}\right)$ and 2-methylimidazole (Hmim) were dissolved in methanol to generate clear solutions, respectively [5], to make monodispersed ZIF-8 crystals with different particle sizes. Then, both of them were mixed together and aged at room temperature for 24 hours. After that, white powders (ZIF- 8 crystals) were precipitated. At room temperature (around $20^{\circ} \mathrm{C}$ ), when $\mathrm{Zn}\left(\mathrm{NO}_{3}\right)_{2}$ was used as zinc source, nano-sized ZIF-8 particles were obtained with an average size of around $50 \mathrm{~nm}$ (hereafter abbreviated as small-sized ZIF-8). When using $\mathrm{Zn}\left(\mathrm{CH}_{3} \mathrm{COO}\right)_{2}$ as zinc source, the particle size increased to around $500 \mathrm{~nm}$ (hereafter abbreviated as middle-sized ZIF-8). At the temperature of $40^{\circ} \mathrm{C}$, using $\mathrm{Zn}\left(\mathrm{CH}_{3} \mathrm{COO}\right)_{2}$ as zinc source, the particle size increased to around $1 \mu \mathrm{m}$ (hereafter abbreviated as large-sized ZIF-8).

In order to get the nanoporous carbon, a quartz boat containing ZIF-8 powder was placed into the vacuum tube furnace. Next, in order to ensure the optimum 
temperature of carbonization, the vacuum tube furnace was heated from room temperature to $950^{\circ} \mathrm{C}, 1000^{\circ} \mathrm{C}$ and $1100^{\circ} \mathrm{C}$ under the protection of argon, with a heating rate of $10^{\circ} \mathrm{C} / \mathrm{min}$. Then the temperature was maintained for $7 \mathrm{~h}$. After natural cooling, the nanoporous carbon (NPC) was obtained.

The AC was purchased from Sinopharm Chemical Regent Co., Ltd., China. Before using, the $\mathrm{AC}$ was pretreated by $\mathrm{HCl}$, and then washed with milli-Q water for several times.

\subsection{Characterization}

The morphology and pore structure of NPC were observed by field emission scanning electron microscope (FE-SEM, Hitachi S-4800). The specific surface area was obtained by the method of multi-point Brunauer-Emmett-Teller (BET), calculated by the adsorption-desorption isotherms of $\mathrm{N}_{2}$ at $77 \mathrm{~K}$. The total volume of mesopore and macropore was the difference between total pore volume and micropore volume which was calculated by the method of V-t plot. The pore width distribution was calculated by the DFT method. The method of X-ray photoelectron spectroscopy (XPS), implemented on a surface analysis system (Thermal ESCALAB 250) using Al Ka radiation, was used to measure the element content of NPC. Fourier transform infrared spectroscopy (FT-IR) was recorded by using a Vertex70, Bruker Vector FTIR spectrometer. The Raman spectrum was obtained via a Renishaw micro-Raman system 2000 spectrometer (Renishaw, UK), which was operated with $\mathrm{He}-\mathrm{Ne}$ laser excitation.

Zeta potential at different $\mathrm{pH}$ was measured by zetasizer nano-ZS equipment (Malvern instrument company, USA). Before the measurement, NPC, SWNT and PAC were dispersed in $1 \mathrm{mM} \mathrm{KCl}$ solution, followed by sonicating for 30 min. The solution $\mathrm{pH}$ was adjusted by $\mathrm{HCl}(1 \mathrm{M})$ and $\mathrm{NaOH}(0.1 \mathrm{M})$ before measurement.

\subsection{Adsorption Experiment}

The batch adsorption experiments on different-sized NPCs of SMX were carried out in $50 \mathrm{~mL}$ quartz vessels with $30 \mathrm{~mL}$ adsorption solution. Background solution containing $0.5 \mathrm{mM} \mathrm{CaCl}_{2}$ and $200 \mathrm{mg} / \mathrm{L} \mathrm{NaN}_{3}$ was mixed with about $2 \mathrm{mg}$ NPCs. The batch adsorption experiments were conducted at $200 \mathrm{rpm}$ on an orbital shaker at fixed temperature of $20^{\circ} \mathrm{C} \pm 1^{\circ} \mathrm{C}$. The concentration of solution was in the range of $5 \mathrm{mg} / \mathrm{L}$ to $100 \mathrm{mg} / \mathrm{L}$. The volume ratio of methanol in solution of each vial was controlled to be less than $0.1 \%$ to minimize cosolvent effect. The vials were sealed and placed in the shaker for 48 hours (kinetics experiments indicated that apparent equilibrium was reached before 48 hours) [6].

The $\mathrm{pH}$ value of solution was 4.82 for SMX, which didn't change during the adsorption process. After adsorption experiments, the adsorbents and the aqueous solution were separated by centrifugation. The concentrations of SMX was determined by a high-performance liquid chromatograph (HPLC, Waters 2695, Waters, USA $)$ equipped with a C18 column $(15 \mathrm{~cm} \times 4.6 \mathrm{~mm} \times 5 \mu \mathrm{m})$ and a UV detector at a column temperature of $30^{\circ} \mathrm{C}$. SMX was detected at $271 \mathrm{~nm}$, 
with a mobile phase of $45: 55$ (v:v) acetonitrile: $0.1 \%$ acetic acid aqueous solution, at flow rate of $1 \mathrm{~mL} / \mathrm{min}$.

In order to investigate the effect of $\mathrm{pH}$, the adsorption experiments were carried out at the concentrations of $10 \mathrm{mg} / \mathrm{L}$ for SMX. $\mathrm{HCl}(1 \mathrm{M})$ and $\mathrm{NaOH}(0.1$ $\mathrm{M})$ were applied to adjust the $\mathrm{pH}$ value of the solution in the range of 2.0-11.0 [7].

\section{Results and Discussion}

\subsection{Characterization of NPCs}

NPC was prepared through carbonization by different-sized ZIF-8, which were named as S-NPC (the traditional structure), M-NPC and L-NPC. Figure 1 showed the geometric shape of the ZIF-8, which usually were demonstrated as rhombic dodecahedra, and also showed the rhombic dodecahedra of three sized ZIF-8, small-sized ZIF-8(S-ZIF8), middle-sized ZIF-8(M-ZIF8) and large-sized ZIF-8 (L-ZIF8). In order to ensure the carbonization being at the optimal temperature, the small-sized ZIF- 8 has been carbonated at three temperatures. At above $908^{\circ} \mathrm{C}$, we can gain the NPCs almost without zinc. So the carbonization temperature is at $950^{\circ} \mathrm{C}, 1000^{\circ} \mathrm{C}$ and $1100^{\circ} \mathrm{C}$. The specific surface area of S-NPC at $950^{\circ} \mathrm{C}, 1000^{\circ} \mathrm{C}$ and $1100^{\circ} \mathrm{C}$ is $1017.5 \mathrm{~m}^{2} / \mathrm{g}, 1378.7 \mathrm{~m}^{2} / \mathrm{g}$ and $809.8 \mathrm{~m}^{2} / \mathrm{g}$, respectively. This result showed that $1000^{\circ} \mathrm{C}$ is the most suitable temperature, at which we can obtain the largest specific surface area. Then explore the adsorption kinetics of SMX on NPCs. The result is in accord with the specific surface area. Table 1 showed the selected physical parameters of NPCs.

According to the pore structure comparison diagram of S-ZIF8 and S-NPC, the specific surface area of S-ZIF8 becomes bigger after carbonization. The size of M-ZIF8 and L-ZIF8 showed same tendency. The zeta potential of these three materials is 3.6, 4.8 and 6.3, respectively. The isoelectric point, the important factor of adsorption, increases with the increase of the crystal size. Figure 2 is

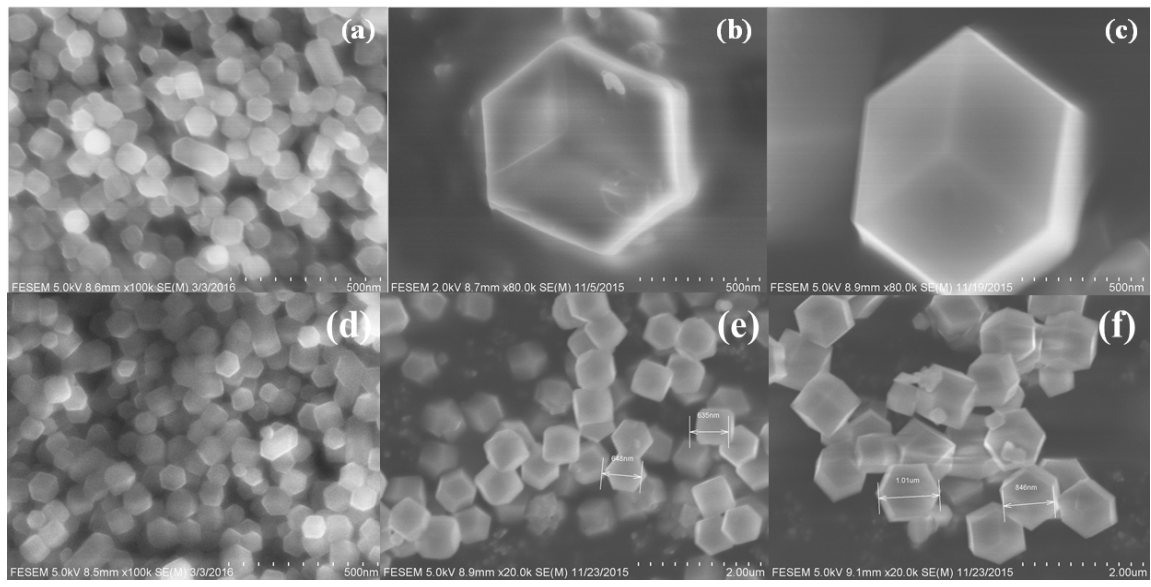

Figure 1. The SEM images of ZIF-8 (a) small-sized ZIF-8(S-ZIF-8); (b) m-sized ZIF-8 (M-ZIF-8); (c) large-sized ZIF-8(L-ZIF-8); (d) small-sized NPC(S-NPC); (e) m-sized NPC(M-NPC); (f) large-sized NPC(M-NPC). 

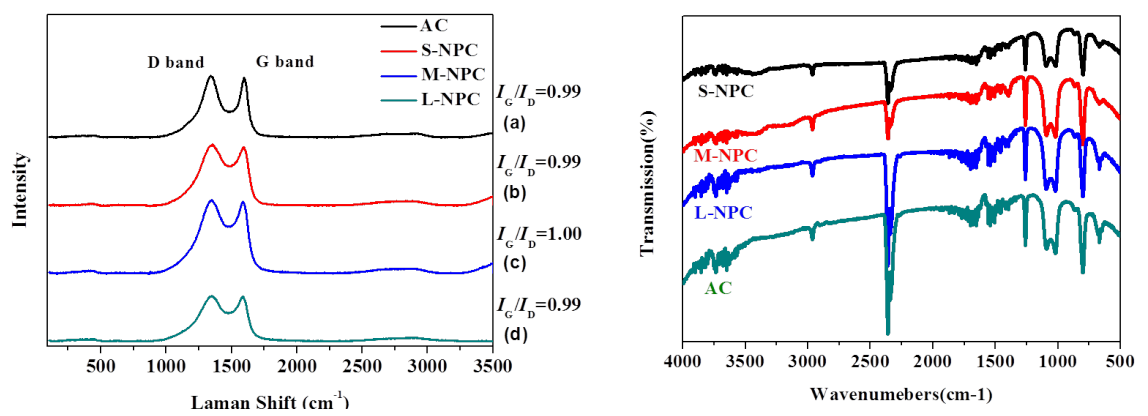

Figure 2. The Raman spectrogram and the FTIR spectra of three NPCs and AC

Table 1. Selected physical parameters of NPCs.

\begin{tabular}{ccccc}
\hline Name & S-NPC & M-NPC & L-NPC & AC \\
\hline Specific surface area $S /\left(\mathrm{m}^{2} / \mathrm{g}\right)$ & 1378.7 & 998.4 & 872.9 & 685.8 \\
Pore volume $V /(\mathrm{mL} / \mathrm{g})$ & 2.90 & 0.62 & 0.55 & 0.60 \\
Pore width $D /(\mathrm{nm})$ & 0.61 & 0.61 & 0.61 & 0.57 \\
\hline
\end{tabular}

the Raman spectrogram and the FTIR spectra of three NPCs and AC. In these kinds of grams, D-band corresponds to defect, while $\mathrm{G}$ band relates to graphite. The relative ratios of $\mathrm{G}$ bands to $\mathrm{D}$ bands $\left(\mathrm{I}_{G} / \mathrm{I}_{D}\right)$ in Raman spectra are important parameters for understanding the crystallization degree of graphitic carbon.

\subsection{Adsorption Kinetics}

For adsorption of SMX on different-sized NPCs, we can see the secondary kinetic fitting is linear (Figure 3). And the fitting results were displayed in Table 2. The simulation results demonstrated the existence of chemical adsorption and the adsorption capacity related to the numbers of active sites on adsorbents.

It was obvious that the adsorption equilibrium was reached within $10 \mathrm{~h}$ for all of the samples, and the rapid adsorption occurred during the first 3 hours, indicating fast initial transfer of chemicals to the adsorbents surface (Figure 3). For all of the adsorbents, adsorption capacity on NPCs was much higher than those on AC.

\subsection{Adsorption Isotherms}

Adsorption isotherms of SMX on the four adsorbents were displayed in Figure 4, all of which were nonlinear. The experimental data was simulated by Langmuir and Freundlich models respectively. The related parameters were listed in Table 3. Langmuir model is based on the hypothesis of monolayer adsorption, with adsorbents possessing uniform adsorption sites on the surface, while Freundlich model is an empirical equation that depicts a multilayer adsorption on heterogeneous surface. It could be observed in Table 3 that, for NPCs and AC, Langmuir model could better fit the adsorption of SMX than Freundlich model, which indicates homogeneous surface of NPCs with identical adsorption sites on it. 

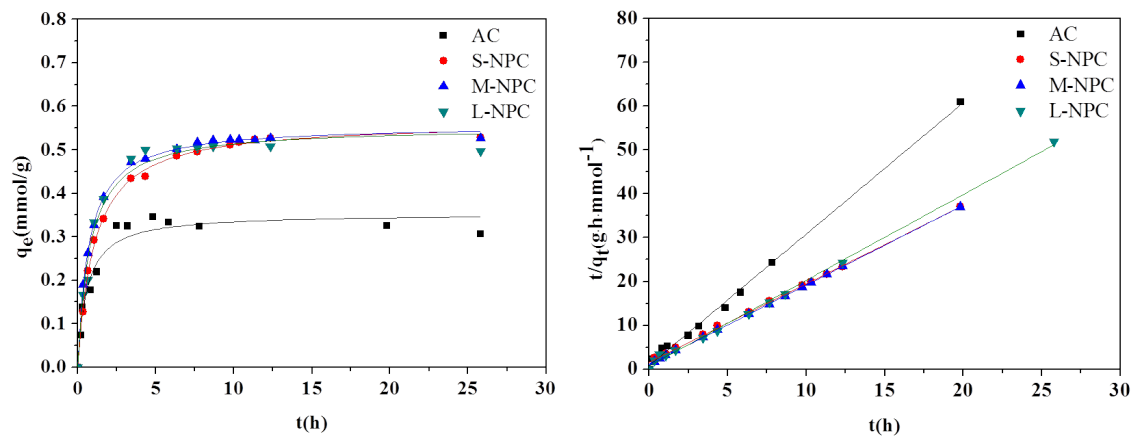

Figure 3. The curve of the amount of contaminants absorbed on NPCs at different time and the kinetics curve of three-sized NPCs.

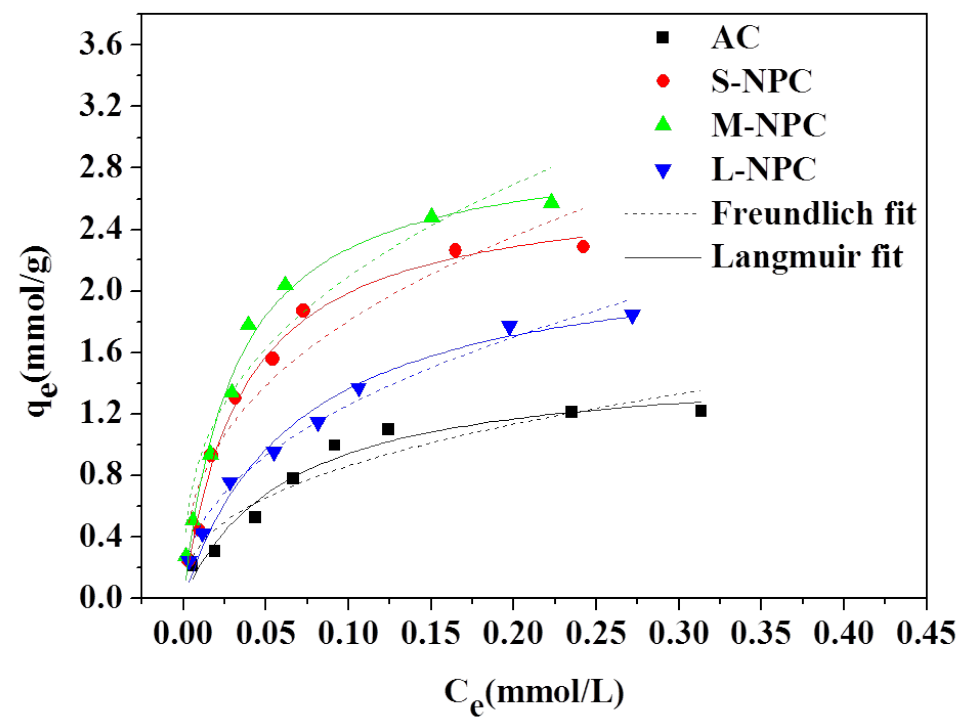

Figure 4. Adsorption isotherms of three-sized NPCs (S-NPC, M-NPC and L-NPC) and AC.

Table 2. Pseudo-second-order parameter of SMX's adsorption on NPCs.

\begin{tabular}{cccccc}
\hline \multirow{2}{*}{ Adsorbent } & $\mathrm{C}(\mathrm{mg} / \mathrm{L})$ & \multicolumn{4}{c}{ Pseudo-second-order parameter } \\
\cline { 3 - 6 } & & $\mathrm{q}_{\mathrm{e}}\left(\mathrm{mmol} \cdot \mathrm{g}^{-1}\right)$ & $\mathrm{V}_{0}\left(\mathrm{mmol} \cdot \mathrm{h}^{-1} \cdot \mathrm{g}^{-1}\right)$ & $\mathrm{K}_{2}\left(\mathrm{~g} \cdot \mathrm{mmol} \cdot \mathrm{h}^{-1}\right)$ & $\mathrm{R}^{2}$ \\
\hline AC & 20 & 0.33 & 1.15 & 10.58 & 0.997 \\
S-NPC & 20 & 0.56 & 0.63 & 1.79 & 0.997 \\
M-NPC & 20 & 0.55 & 1.00 & 1.82 & 0.999 \\
L-NPC & 20 & 0.54 & 0.71 & 2.35 & 0.998 \\
\hline
\end{tabular}

For $\mathrm{AC}$, the maximum adsorption capacities $\left(\mathrm{q}_{\mathrm{m}}\right)$ of SMX were lower than those of NPCs, demonstrating the excellent adsorption capacity of NPCs. As shown in Table 3, the $\mathrm{q}_{\mathrm{m}}$ of SMX over NPCs were 686, 757 and $582 \mathrm{mg} / \mathrm{g}$ respectively, and the $\mathrm{q}_{\mathrm{m}}$ of M-NPC was 2 times larger than that of AC. The higher adsorption capacity of NPCs may be attributed to the much higher specific surface area. The excellent adsorption capacity of NPCs implied that nanoporous 
Table 3. Adsorption equilibrium constants of Freundlich model and Langmuir model for contaminants adsorption on NPCs and AC.

\begin{tabular}{ccccccc}
\hline Adsorbent & \multicolumn{3}{c}{ Langmuir constants } & \multicolumn{3}{c}{ Freundlich constants } \\
\hline & $\mathrm{q}_{\mathrm{m}}(\mathrm{mmol} / \mathrm{g})$ & $\mathrm{b}(\mathrm{l} / \mathrm{mmol})$ & $\mathrm{R}^{2}$ & $\mathrm{~K}_{\mathrm{F}}\left(\mathrm{mmol}^{(1-\mathrm{n})} \mathrm{L}^{\mathrm{n}} / \mathrm{g}\right)$ & $\mathrm{n}$ & $\mathrm{R}^{2}$ \\
\hline $\mathrm{S}-\mathrm{NPC}$ & 2.70 & 27.98 & 0.988 & 4.36 & 0.38 & 0.909 \\
$\mathrm{M}-\mathrm{NPC}$ & 2.98 & 32.39 & 0.986 & 4.83 & 0.36 & 0.931 \\
$\mathrm{~L}-\mathrm{NPC}$ & 2.29 & 14.69 & 0.973 & 3.43 & 0.44 & 0.986 \\
$\mathrm{AC}$ & 1.54 & 15.85 & 0.960 & 2.14 & 0.40 & 0.868 \\
\hline
\end{tabular}

carbon derived from MOFs would be a promising adsorbents used for wastewater treatment in the future.

\section{Acknowledgements}

This work was supported by National Natural Science Foundation of China (grant no. 21590813), and the Fundamental Research Funds for the Central Universities (grant no. DUT16TD02).

\section{References}

[1] Baquero, F., Martínez, J.L. and Cantón, R. (2008) Antibiotics and Antibiotic Resistance in Water Environments. Current Opinion in Biotechnology, 19, 260-265. http://www.sciencedirect.com/science/article/pii/S0958166908000591 https://doi.org/10.1016/j.copbio.2008.05.006

[2] Braschi, I., Blasioli, S., Gigli, L., Gessa, C.E., Alberti, A. and Martucci, A. (2010) Removal of Sulfonamide Antibiotics from Water: Evidence of Adsorption into an Organophilic Zeolite Y by Its Structural Modifications. Journal of Hazardous Materials, 178, 218-225.

http://www.sciencedirect.com/science/article/pii/S0304389410000993 https://doi.org/10.1016/j.jhazmat.2010.01.066

[3] Torad, N.L., Hu, M., Kamachi, Y., Takai, K., Imura, M., Naito, M. and Yamauchi, Y. (2013) Facile Synthesis of Nanoporous Carbons with Controlled Particle Sizes by Direct Carbonization of Monodispersed Zif-8 Crystals. Chemical Communications, 49, 2521-2523.

http://pubs.rsc.org/is/content/articlehtml/2013/cc/c3cc38955c https://doi.org/10.1039/c3cc38955c

[4] Chaikittisilp, W., Ariga, K. and Yamauchi, Y. (2013) A New Family of Carbon Materials: Synthesis of Mof-Derived Nanoporous Carbons and Their Promising Applications. Journal of Materials Chemistry A, 1, 14-19. http://pubs.rsc.org/is/content/articlehtml/2013/ta/c2ta00278g https://doi.org/10.1039/C2TA00278G

[5] Zhang, L., Su, Z., Jiang, F., Yang, L., Qian, J., Zhou, Y. and Hong, M. (2014) Highly Graphitized Nitrogen-Doped Porous Carbon Nanopolyhedra Derived from ZIF-8 Nanocrystals as Efficient Electrocatalysts for Oxygen Reduction Reactions. Nanoscale, 6, 6590-6602.

http://pubs.rsc.org/en/content/articlehtml/2014/nr/c4nr00348a https://doi.org/10.1039/c4nr00348a

[6] Li, X., Zhao, H., Quan, X., Chen, S., Zhang, Y. and Yu, H. (2011) Adsorption of Ionizable Organic Contaminants on Multi-Walled Carbon Nanotubes with Different 
Oxygen Contents. Journal of Hazardous Materials, 186, 407-415.

http://www.sciencedirect.com/science/article/pii/S0304389410014226 https://doi.org/10.1016/j.jhazmat.2010.11.012

[7] Li, X., Chen, S., Quan, X. and Zhang, Y. (2011) Enhanced Adsorption of PFOA and PFOS on Multiwalled Carbon Nanotubes under Electrochemical Assistance. Environmental Science \& Technology, 45, 8498-8505. https://doi.org/10.1021/es202026v

Submit or recommend next manuscript to SCIRP and we will provide best service for you:

Accepting pre-submission inquiries through Email, Facebook, LinkedIn, Twitter, etc. A wide selection of journals (inclusive of 9 subjects, more than 200 journals)

Providing 24-hour high-quality service

User-friendly online submission system

Fair and swift peer-review system

Efficient typesetting and proofreading procedure

Display of the result of downloads and visits, as well as the number of cited articles

Maximum dissemination of your research work

Submit your manuscript at: http://papersubmission.scirp.org/

Or contact gep@scirp.org 